\title{
Chartres, 48 rue du Faubourg-Guillaume
}

$\mathrm{n}^{\circ} 064576$

Dominique Joly

\section{(2) OpenEdition}

Journals

Édition électronique

URL : http://journals.openedition.org/adlfi/13970

ISSN : 2114-0502

Éditeur

Ministère de la culture

Référence électronique

Dominique Joly, "Chartres, 48 rue du Faubourg-Guillaume », ADLFI. Archéologie de la France-

Informations [En ligne], Centre, mis en ligne le 23 janvier 2015, consulté le 19 avril 2019. URL : http:// journals.openedition.org/adlfi/13970

Ce document a été généré automatiquement le 19 avril 2019

(c) Ministère de la Culture et de la Communication, CNRS 


\title{
Chartres, 48 rue du Faubourg- Guillaume
}

$n^{\circ} 064576$

\author{
Dominique Joly
}

Lien Atlas (MCC) :

http://atlas.patrimoines.culture.fr/atlas/trunk/index.php?

ap_theme=DOM_2.01.02\&ap_bbox=1.460;48.427;1.550;48.469

1 Sur le versant du coteau dominant la rive droite de l'Eure, dans le quartier du FaubourgGuillaume, un projet de construction d'une maison individuelle sur un vide sanitaire de $1 \mathrm{~m}$ a entraîné une fouille d'évaluation sous la forme de cinq sondages d'ampleur limitée. Les sondages couvrent environ $15 \%$ de la zone détruite par les travaux. La profondeur des sondages varie entre $0,8 \mathrm{~m}$ et $1,5 \mathrm{~m}$.

2 Ce terrain appartient à la périphérie de la ville gallo-romaine d'Autricum. À proximité, ont été mis au jour de nombreux vestiges d'habitats gallo-romains (sites de la Croix-Thibault et du Faubourg-Guillaume). Les éléments les plus significatifs se trouvent au sud du terrain concerné : une voie romaine à $40 \mathrm{~m}$, et, à une centaine de mètres, une nécropole et un atelier de potiers gallo-romains (site Saint-Barthélémy).

3 Les sondages ont montré l'importance des remblais apportés au XIX ${ }^{\mathrm{e}} \mathrm{s}$. afin d'aménager des terrasses constructibles dans ce secteur. Aucun vestige antérieur n'a été mis en évidence. 
INDEX

Index chronologique : ép. contemporaine

Index géographique : Centre, Eure-sur-Loir, Chartres

Mots-clés : remblai

operation Évaluation archéologique (EV) 